\title{
the index optimization of Teaching Quality Evaluation based on Boolean Matrix algorithm in Rough Set
}

\author{
Hongli YUAN ${ }^{1, a,{ }^{*}}$, Sumin YANG $^{1}$, Lei WANG ${ }^{2, b}$, Huiqian ZHANG ${ }^{1}$ \\ ${ }^{1}$ Department of Information Engineering,Mechanical Engineering \\ College,Shijiazhuang,050003,China \\ ${ }^{2}$ The School of Information Technology, Hebei Institute of \\ Communications,Shijiazhuang,050071,China \\ ayuanhongli607@163.com, bwangleilei402@163.com
}

\begin{abstract}
Keywords: Teaching quality; Boolean matrix; decision rules
Abstract. The objective evaluation of teachers' teaching quality can stimulate teachers' teaching enthusiasm and improve teaching quality. In this paper we apply an algorithm based on Boolean matrix in rough set for data analysis on the evaluation of teachers' teaching quality, optimize the evaluation index and generate easy and valid decision rules. The correctness and effectiveness of the decision rules are verified by theoretical analysis and experiment simulation.
\end{abstract}

The quality of teaching is the life of colleges and universities, and the quality evaluation of the teachers' teaching is the means to encourage teachers to devote themselves to reform teaching and improve the teaching quality. The objective and fair evaluation of the teachers' teaching work, is a powerful tool of the school teaching management department for teaching quality control and management. At present, the evaluation of the teaching quality in colleges and universities is mainly based on expert evaluation, student evaluation and leader evaluation. Because of people's feeling and experience, the subjectivity of the evaluation is relatively large. It is very difficult to ensure the teaching quality objectively and fairly. Rough set can be used to handle fuzzy and imprecise problems. And it can mine potential, valuable knowledge objectively from the large numbers of data without any prior knowledge. So In this paper we propose an algorithm for the evaluation of teachers' teaching quality, based on Boolean matrix in rough set optimize the evaluation index and generate easy and valid decision rules. It can provide some guidance for the evaluation of teachers' teaching quality objective and fairly.

\section{attribute reduction algorithm based on Boolean Matrix in Rough Set}

basic theory Definition ${ }^{[6]}$ :information system $I S=(U, A, V, f)$, where $U$ is a universe, and its partition is $X=\left(X_{1}, X_{2}, \ldots, X_{m}\right)$ with attribute set $A=\left\{a_{1}, a_{2}, \ldots, a_{n}\right\}$, there is only one number $i$ for every set $\left(K_{k}, X_{l}\right)(1 \leq k<l \leq m)$,

$$
i=(l-1)(n-1)-\frac{2(l-1)}{2}+(l-k)
$$

One $\mathrm{i}$ is given to unique correspondence the set pair $\left(X_{k}, X_{2}\right)$.

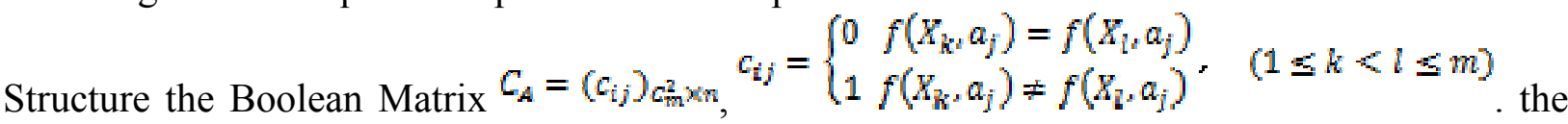
$\left(X_{k}, X_{l}\right)$ unique correspondence the set pair of number $\mathrm{i}, \mathrm{j}$ unique correspondence the number of attribute $a_{j}$.

Definition $^{[7]}$ : information system $I S=(U, A, V, f)$, attribute set $\mathbb{R} \subset A$, delete all lines which value of attribute of set $R$ in this column is 1 from Boolean matrix $C_{A}$,called the rest of Boolean matrix $C_{A}$ is $C_{A \backslash \Omega}$. 
Statement $1^{[8]}$ if there is only one 1 in some line in Boolean Matrix, the rest are 0 , so the column which the 1 corresponding to the attribute is a part of the core. All attributes which 1 corresponding form the core of the information system; if there is no lines like this ,the core is null.

Statement 2 the relation of The core attributes and reduction is the following: $\operatorname{CORE}(A)=\cap \operatorname{RED}(A)$.

Theorem $1^{[6]}$ information system $I S=(U, A, V, f), A_{1} \subseteq A$, if the non-zero line numbers of $C_{A 1}$ and $C_{A}$ are equal , that is to say $I N D\left(A_{1}\right)=I N D(A)$

Theorem $2^{[6]}$ information system $I S=(U, A, V, f)$, the sufficient and necessary condition of $A_{1} \subseteq A$ being a reduction of $A$ is that the following two conditions are founded:

(1)the non-zero line numbers of $C_{A 1}$ and $C_{A}$ are equal, that is to say, the ability of the classification of $A_{1}$ and $A$ is equal.

(2)if we delete any columns of $C_{A 1}$, there will appear zero lines, $C_{A 1}$ independence.

Inference 1 information system $I S=(U, A, V, f)$, in $C_{A \backslash \operatorname{CoRE}(A)}, A_{1} \subseteq A-\operatorname{CORE}(A)$, if the non-zero lines of $A_{1}$ and $C_{A \backslash \operatorname{Conz}(A)]}$ are equal, the non-zero lines of $C_{\left[A_{1}, C O R E(A)\right]}$ and $C_{A}$ are equal.

Prove:

According to the definition, all lines which the value of this column the attribute in CORE(A) corresponding to is 1 are deleted from the boolean matrix, the rest is call $C_{A \bigvee \cos (A)}$. So set of matrix $C_{A \backslash \operatorname{CoRz}(A)}$ is the set which $\operatorname{CORE}(A)$ of information system $I S$ can not distinguish, and The line numbers of $C_{A \backslash C O R E(A)}$ is the line numbers which $\operatorname{CORE}(A)$ can not distinguish. In $C_{A \backslash C O R E(A) \text {, if the }}$

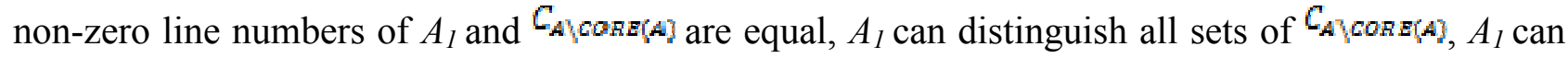
distinguish all the sets which $\operatorname{CORE}(A)$ can not distinguish. So, $\left\{A_{1}, \operatorname{CORE}(A)\right\}$ can distinguish all sets of $C_{A}$, the non-zero line numbers of $\mathrm{C}_{\left[\mathrm{A}_{1}, \operatorname{CORE}(A)\right]}$ and $\mathrm{C}_{\AA}$ are equal. That's all.

Inference 2 if there is only one 1 in every line of $C_{A \backslash \operatorname{Cos} z(A)]}$, and the attribute set the matrix corresponding to is called $A_{1} \subseteq A-\operatorname{CORE}(A)$, so $\left\{A_{1}, \operatorname{CORE}(A)\right\}$ must be a attribute reduction of $I S$.

Prove:

(1) In $C_{A \backslash \text { Con } E(A)}$, if there is one 1 in every line, this is to say $A_{1}$ can distinguish all sets in matrix $C_{A \backslash C O R E(A)}$, according to inference1, the non-zero line numbers of $C_{\left[A_{1}, C O R E\{A\}\right]}$ and $C_{A A}$ are equal.

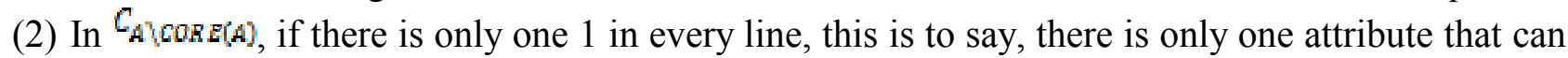
distinguish this set. If the attribute is deleted, there must be appeared zero lines and no attribute can distinguish this set. The non-zero line numbers of $C_{\left[A_{1}-[a] \operatorname{CoR}[A]\right)}$ is 1 less than $C_{A}$. So $C_{\left[A_{1}, C O R E(A)\right]}$ is independent.

According to Theorem 2, attribute set $\left\{A_{1}, \operatorname{CORE}(A)\right\}$ must be attribute reduction of $I S$, that's all. Algorithm description Firstly, lines can be processed, core attribute can be found and core attribute is added directly to the attribute reduction set $R$, then $C_{A \mid R}$ is got through computing. Secondly, the matrix is decomposed into the matrix in which there is only one 1 line. Attribute sets every matrix corresponding to and core attribute constitute the attribute reduction set.

Input: information system $I S=(U, A, V, f)$

Output: all attribute reduction sets $R$ of information system $I S$.

Step1: structure all attribute sets $R$ according to information system.

Step2: initialize the attribute reduction sets $R=\emptyset$.

Step3: the sum of every line in the Boolean matrix $C_{A}$ is computed, add the attribute which the column whose value is 1 in these lines corresponding to is added into attribute reduction set $R . R=R \cup\{a\}$, then $C_{A \mid R}$ is got through computing. If there is no lines whose sum is 1, go step5.

Step 4: $C_{A \backslash R}$ is decomposed into some matrix in which there is 1 in very line and there are not all 1 in very column. And then the attribute whose column is 1 is added into $R=R \cup\{a\}, R$ is the result. The matrix numbers after decomposing is the attribute reduction numbers of the information system $I S$.

Step5: output $R$, the end. 


\section{examples of algorithm application}

According to the actual situation of our college, the quality evaluation index system of the teaching quality is formulated, Including: expert evaluation, student assessment. According to the courses, it is also divided into theoretical and practical evaluation index. Due to space reasons, we only introduce expert evaluation index, including fifteen index, as shown in table 1.

Table 1 evaluation index of teachers' teaching quality

\begin{tabular}{|c|c|}
\hline $\begin{array}{c}\text { Serial } \\
\text { number }\end{array}$ & Evaluation index \\
\hline 1 & Teaching preparation \\
\hline 2 & $\begin{array}{l}\text { The teaching goal is clear, accords with the standard of curriculum and is } \\
\text { suitable for students' characteristics }\end{array}$ \\
\hline 3 & Substantial content and appropriate information \\
\hline 4 & Accurate lecturing and strict logic \\
\hline 5 & Pay attention to basic concepts, basic principles, and basic skills training \\
\hline 6 & $\begin{array}{l}\text { Carry out creative restructuring of teaching content, and embody the inner } \\
\text { relationship of knowledge }\end{array}$ \\
\hline 7 & Pay Attention to the introduction of knowledge into teaching reasonably \\
\hline 8 & $\begin{array}{l}\text { Pay attention to connecting theory to practice and to the training of students } \\
\text { ability }\end{array}$ \\
\hline 9 & $\begin{array}{l}\text { Encourage students to explore, think, question, and be good at inspiring } \\
\text { thinking }\end{array}$ \\
\hline 10 & $\begin{array}{l}\text { Stimulate learning interest, create a harmonious and interactive teaching } \\
\text { atmosphere }\end{array}$ \\
\hline 11 & Appropriate use of various teaching methods to enhance teaching effect \\
\hline 12 & Language, gesture and text are infectious \\
\hline 13 & Hard work and dedication, rigorous scholarship \\
\hline 14 & $\begin{array}{l}\text { Pay attention to the students' ideological situation, strict at students, } \\
\text { teaching while educating people }\end{array}$ \\
\hline 15 & The teacher has a good moral character and a good teacher's image \\
\hline
\end{tabular}

rough set is employed in index optimization of these index. Firstly 10 samples is extracted randomly though analytic study from 366 samples of teaching evaluation base at the second term of 2014. $U_{1}$ presents sample $1, U_{2}$ presents sample 2 . $a_{1}$ presents evaluation index 1 - Teaching preparation; $a_{2}$ Present evaluation index 2- The teaching goal is clear, accords with the standard of curriculum and is suitable for students' characteristics. And so on, this system decision table is built, as shown in table 2 . 
Table 2 information system

\begin{tabular}{|c|c|c|c|c|c|c|c|c|c|c|c|c|c|c|c|}
\hline & $\mathrm{a}_{1}$ & $\mathrm{a}_{2}$ & $\mathrm{a}_{3}$ & $\mathrm{a}_{4}$ & $\mathrm{a}_{5}$ & $\mathrm{a}_{6}$ & $\mathrm{a}_{7}$ & $\mathrm{a}_{8}$ & $\mathrm{a}_{9}$ & $\mathrm{a}_{10}$ & $\mathrm{a}_{11}$ & $\mathrm{a}_{12}$ & $\mathrm{a}_{13}$ & $\mathrm{a}_{14}$ & $\mathrm{a}_{15}$ \\
\hline $\mathrm{U}_{1}$ & 10 & 9.5 & 10 & 9.5 & 9 & 8 & 8 & 8.5 & 9.5 & 9 & 9 & 9 & 10 & 8.5 & 10 \\
\hline $\mathrm{U}_{2}$ & 10 & 10 & 9.5 & 10 & 10 & 9 & 8 & 9 & 10 & 10 & 9.5 & 9.5 & 9.5 & 9 & 10 \\
\hline $\mathrm{U}_{3}$ & 8.5 & 8 & 8.5 & 8.5 & 8 & 8 & 8.5 & 8 & 8 & 7 & 8 & 7.5 & 8 & 8 & 8 \\
\hline $\mathrm{U}_{4}$ & 8.5 & 8 & 8 & 9.5 & 8 & 8.5 & 8 & 8 & 10 & 10 & 9 & 8 & 8.5 & 8 & 8 \\
\hline $\mathrm{U}_{5}$ & 10 & 8.5 & 9.5 & 8.5 & 10 & 8.5 & 9.5 & 9 & 9 & 9 & 9 & 9 & 9 & 9 & 9.5 \\
\hline $\mathrm{U}_{6}$ & 9 & 9 & 7.5 & 8 & 8.5 & 8.5 & 8 & 8 & 8.5 & 8.5 & 7.5 & 7.5 & 8.5 & 8.5 & 8.5 \\
\hline $\mathrm{U}_{7}$ & 9.5 & 9 & 9 & 9 & 9.5 & 8.5 & 8.5 & 9 & 8.5 & 8.5 & 8.5 & 9 & 9.5 & 9 & 9 \\
\hline $\mathrm{U}_{8}$ & 9 & 8.5 & 8 & 7 & 7 & 6.5 & 7.5 & 8.5 & 7.5 & 6.5 & 7.5 & 7 & 8.5 & 8.5 & 9.5 \\
\hline $\mathrm{U}_{9}$ & 10 & 9.5 & 9.5 & 9.5 & 9.5 & 8 & 8.5 & 9 & 8.5 & 8 & 8.5 & 8.5 & 9.5 & 9.5 & 9.5 \\
\hline $\mathrm{U}_{10}$ & 10 & 9.5 & 9.5 & 9.5 & 9.5 & 8 & 8.5 & 9 & 6.25 & 8 & 8.5 & 8.5 & 9.5 & 9.5 & 9.5 \\
\hline
\end{tabular}

Secondly, the Boolean matrix is structured, after attribute reduction using this algorithm of this paper, First, core attribute a is got, $\mathrm{d}(\mathrm{a} 9, \mathrm{R})=41, \mathrm{R}=\{\mathrm{a} 9\}, C_{A \backslash R}$ is got through 111111010011111

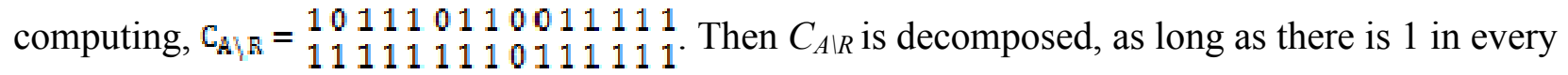
111101000101011

line. Through this matrix, all of the attribute $\mathrm{a}_{1}, \mathrm{a}_{3}, \mathrm{a}_{4}, \mathrm{a}_{12}, \mathrm{a}_{14}, \mathrm{a}_{15}$ can distinguish the rest samples by themselves. So they are deleted from the matrix, and constitute attribute reduction with core attribute separately. They are: $\left\{\mathrm{a}_{1}, \mathrm{a}_{9}\right\},\left\{\mathrm{a}_{3}, \mathrm{a}_{9}\right\},\left\{\mathrm{a}_{4}, \mathrm{a}_{9}\right\},\left\{\mathrm{a}_{9}, \mathrm{a}_{12}\right\},\left\{\mathrm{a}_{9}, \mathrm{a}_{14}\right\},\left\{\mathrm{a}_{9}, \mathrm{a}_{15}\right\}$, and the matrix becomes 010011010010100

$\mathrm{C}_{A \backslash \mathrm{E}^{\prime}}=0000101100101000$. 010001000100000

distinguish ability of $a_{2}$ and $a_{6}$ is equal. So attribute reduction is obtained by $a_{5}$ and $a_{2}$ :

$\left\{\mathrm{a}_{2}, \mathrm{a}_{5}, \mathrm{a}_{9}\right\},\left\{\mathrm{a}_{2}, \mathrm{a}_{7}, \mathrm{a}_{9}\right\},\left\{\mathrm{a}_{5}, \mathrm{a}_{10}, \mathrm{a}_{9}\right\}$. The attribute reduction sets are:

$\left\{\mathrm{a}_{1}, \mathrm{a}_{9}\right\},\left\{\mathrm{a}_{3}, \mathrm{a}_{9}\right\},\left\{\mathrm{a}_{4}, \mathrm{a}_{9}\right\},\left\{\mathrm{a}_{9}, \mathrm{a}_{12}\right\},\left\{\mathrm{a}_{9}, \mathrm{a}_{14}\right\},\left\{\mathrm{a}_{9}, \mathrm{a}_{15}\right\},\left\{\mathrm{a}_{2}, \mathrm{a}_{5}, \mathrm{a}_{9}\right\},\left\{\mathrm{a}_{2}, \mathrm{a}_{7}, \mathrm{a}_{9}\right\},\left\{\mathrm{a}_{5}, \mathrm{a}_{10}, \mathrm{a}_{9}\right\},\left\{\mathrm{a}_{2}, \mathrm{a}_{8}, \mathrm{a}_{9}\right\},\left\{\mathrm{a}_{8}, \mathrm{a}_{10}, \mathrm{a}_{9}\right\}$, $\left\{\mathrm{a}_{2}, \mathrm{a}_{11}, \mathrm{a}_{9}\right\},\left\{\mathrm{a}_{11}, \mathrm{a}_{10}, \mathrm{a}_{9}\right\},\left\{\mathrm{a}_{2}, \mathrm{a}_{13}, \mathrm{a}_{9}\right\},\left\{\mathrm{a}_{13}, \mathrm{a}_{10}, \mathrm{a}_{9}\right\},\left\{\mathrm{a}_{6}, \mathrm{a}_{5}, \mathrm{a}_{9}\right\},\left\{\mathrm{a}_{6}, \mathrm{a}_{7}, \mathrm{a}_{9}\right\}$.

The attribute importance of these fifteen attributes are shown in table 3.

Table 3 attribute importance value

\begin{tabular}{|c|c|c|c|c|c|c|c|c|c|c|c|c|c|c|c|}
\hline attribute & a1 & a2 & a3 & a4 & a5 & a6 & a7 & a8 & a9 & a10 & a11 & a12 & a13 & a14 & a15 \\
\hline importance & 5.95 & 7.02 & 6.85 & 6.85 & 7.21 & 5.77 & 5.95 & 5.59 & 7.39 & 7.39 & 6.85 & 7.21 & 6.67 & 6.49 & 6.85 \\
\hline
\end{tabular}

In this sample data, importance of every attribute is shown in table 3 . We the biggest attribute importance $\left\{\mathrm{a}_{5}, \mathrm{a}_{10}, \mathrm{a}_{9}\right\}$ is chose, and decision rules are got as shown in table 4 .

Table 4 decision rules

\begin{tabular}{|c|c|c|}
\hline & range & result \\
\hline \multirow{3}{*}{$a_{5}+a_{9}+a_{10}$} & {$[9,10]$} & excellent \\
\cline { 2 - 3 } 3 & {$[8,9)$} & good \\
\cline { 2 - 3 } & {$[7,8)$} & middle \\
\cline { 2 - 3 } & {$[6,7)$} & qualified \\
\hline
\end{tabular}

The decision rules are verified by 366 sample data in 2014, and there are 42 samples which do not comply with the decision rules and the rest do. The success rate is $88.52 \%$.

\section{Conclusion}

In this paper an algorithm is employed based on Boolean matrix in rough set for data analysis of the evaluation of teachers' teaching quality of our college in 2014 and finally a new attribute reduction is got, generate decision rules are got and verified. Compared with old method of evaluation of teachers' 
teaching quality, this evaluation system of teachers' teaching quality established by rough set overcome subjectivity and inefficiency, It can evaluate teachers' teaching quality more objectively, more easily and more efficiently. It has a strong practical value.

\section{References:}

[1] Pawlak Z. Rough Sets[J]. International Journal of Computer and Information Sciences, 1982,11:341-356

[2] Xie, Yan-Hong. a new heuristic attribute reduction method based on Boolean matrix[J].International Conference on intelligent Structure and Vibration Control,ISVC2011,605-609 [3] Wang Bin-Li, Shen Yan Guang. Improvement of Apriori algorithm based on Boolean matrix [J].2010 international Conference on Micro Nano Devices, Structure and Computing Systems,MNDSCS2010,144-148

[4] Zhang Chen-guang, $\mathrm{Xu}$ Zhang-yan, Zhou Jian-hua. fast attribute reduction algorithm for incomplete decision table based on Boolean conflict matrix[J].Computer Applications and Software, 2014,31(8):257-260 In Chinese

[5] CHEN Jun-ming. Extracting Spatial Association Rules Based on Boolean Matrix[J]. Geomatics\&spatial information technology, 2014,37(5):123-126 In Chinese

[6] LI Longxing, YUN Shiwei, YANG Bingru. Boolean Matrix Presentation of Rough Set Concept and Operation[J].Computer Engineering, 2005,31(14):16-17 In Chinese

[7] LI Longxing, YUN Shiwei, YANG Bingru. Attribute Reduction Heuristic Algorithm in Rough Sets Based on Boolean Matrix[J]. Computer Engineering, 2007,33(10):205-206 In Chinese

[8] TONG Xin an, YUN Shi wei, ZHANG Yong sheng. An Algorithm for Attribute Reduction in

Rough Sets Based on Boolean Matrix[J].Journal of Luoyang Institute of Science and Technology(Natural Science Edition), 2009,19(1):69-73 In Chinese

[9] HUANG Long jun, ZHANG Zhi ming, ZHOU Cai ying, HUANG Ming-he. Method of Data Reduction Based on Boolean Matrix[J].Computer Engineering and Applications[J], 2006.34:160-161 In Chinese

[10] YUN Shi wei, ZHANG Yong sheng. Application on algorithm of permutation matrix in rough set attribute reduction[J]. Computer Engineering and Applications[J], 2009,45(13):45-46 In Chinese

[11] MIAO Duoqian, LI Dao guo. Rough Set Theory Algorithms and Applications[M]. Rsinghua university press.2008:24-81 In Chinese

[12] MENG Ren, XU ZHANG yan, YANG Bing ru. Matrix Description for Attribute Reduction Based on Skowron Discernibility Matrix[J].Computer Engineering, 2010,36(17):54-56 In Chinese

[13] GAO Yi, YAN Hong wen. Attibute reduction of rough set based on differential evolutionary algorithm[J] ,2010,30(9):2329-2331 In Chinese

[14] HOU Feng, LIU Feng nian. Incremental algorithms for attribute reduction based on discernibility matrix and reduction tree. Computer Engineering and Applications,2010,46(11):125-127 In Chinese [15] CHEN Li wan, XIANG Chun rong. Exploration and research of changing Evalution mechanism of the teaching quality[J].Chinese university teaching, 2014,7:8-78,83 In Chinese 